\title{
Synthesis and Characterization of Starch Coated Natural Magnetic Iron Oxide Nanoparticles for the Removal of Methyl Orange Dye from Water
}

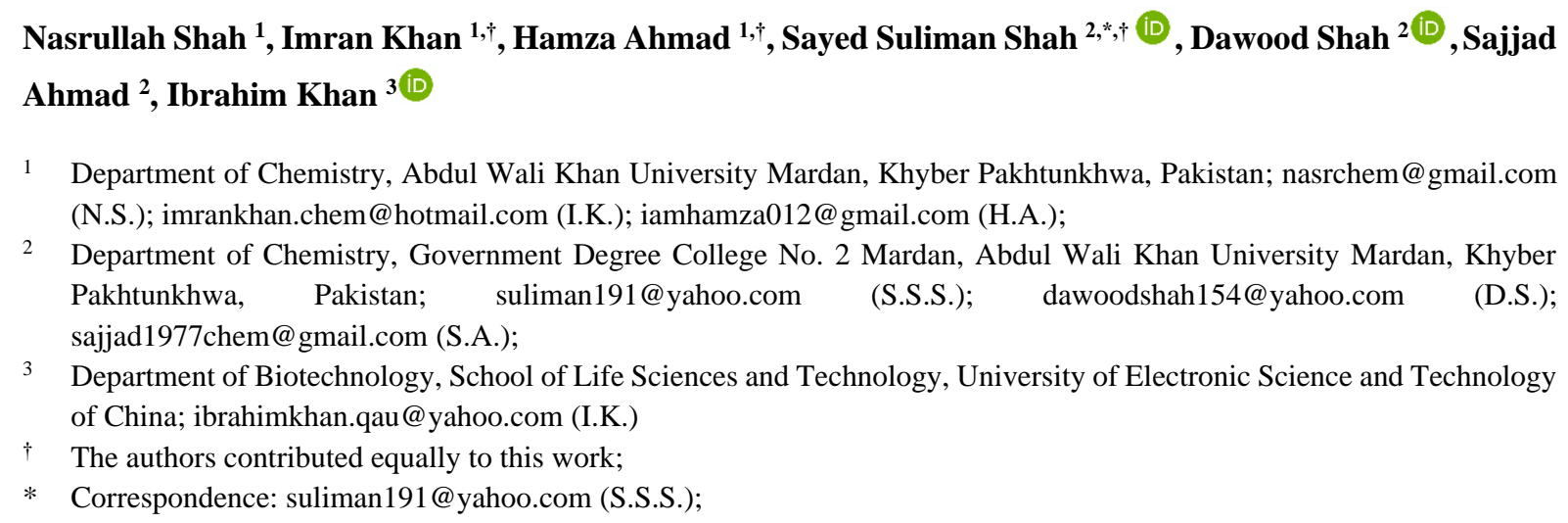

Received: 17.02.2021; Revised: 15.04.2021; Accepted: 19.04.2021; Published: 8.05.2021

\begin{abstract}
The $\mathrm{Fe}_{3} \mathrm{O}_{4}$ nanoparticles were synthesized from natural iron sand by dissolving it in $\mathrm{HCl}$ and precipitated by $\mathrm{NaOH}$. Two solutions of iron rocks were treated, one without starch and one with starch, followed by $\mathrm{NaOH}$. Both samples were characterized by X-ray Diffractometer (XRD), Scanning Electron Microscopy (SEM), Fourier Transform Infrared (FT-IR), and Energy Dispersive X-ray (EDX) to record the crystallinity, morphology, and coating of starch on the $\mathrm{Fe}_{3} \mathrm{O}_{4}$ surface. The XRD pattern shows the presence of crystalline structures between bare and coated magnetic particles. SEM shows its morphological structure. EDX shows the elemental composition Fe present up to $75 \%$ in rocks. The removal of methyl orange dye is investigated and found $75 \%$ removal efficiency at the optimum condition at $\mathrm{pH} 6$ at 120 minutes.
\end{abstract}

Keywords: iron; natural magnetic iron oxide nanoparticles; starch coating; synthesis; characterization; methyl orange dye.

(C) 2021 by the authors. This article is an open-access article distributed under the terms and conditions of the Creative Commons Attribution (CC BY) license (https://creativecommons.org/licenses/by/4.0/).

\section{Introduction}

Nanotechnology is a multidisciplinary science that studies matter in the range of onebillionth of a meter $\left(10^{9} \mathrm{~m}\right.$, which is equivalent to $\left.1 \mathrm{~nm}\right)$ [1]. According to the United State National Nanotechnology Initiative (USNNI), nanotechnology is the study of measuring, modeling, and manipulating matter at the atomic and molecular scale, i.e., at dimensions between approximately 1 and $100 \mathrm{~nm}$ [2]. It deals with many fields of science such as chemical sciences, electronics, pharmaceutical sciences, advanced materials, information technology, agricultural sciences, physics, and Nano-medicines, etc. [3-5]. In rapid nanotechnology growth, nanoparticles (NPs) are at the forefront. In several human activities, their peculiar sizedependent properties make these materials invaluable and superior [6].

Magnetic nanoparticles are of great interest for researchers of several fields, including biotechnology, biomedicine, magnetic fluids, magnetic resonance imaging, and environmental 
remediation [7-9]. There are many uses for magnetic nanoparticles, such as contrast improvement of magnetic resonance imaging [10], cell isolation [11], hyperthermia, and drug delivery [12], etc. These applications place stringent specifications on nanoparticles' physical, chemical, and pharmacological properties, including chemical composition, crystal structure, granulometric uniformity, magnetic activity and surface structure, adsorption characteristics, solubility, and low toxicity $[13,14]$. Magnificent attention has been paid to iron oxide among magnetic nanoparticles. These nanoparticles at room temperature are super-paramagnetic; however, due to hydrophobic interactions between the particles, they agglomerate and form large clusters, resulting in increased particle size and low colloidal stability [15]. In this case, the clusters show strong magnetic dipole attractions and ferromagnetic activity [16]. Magnetic particles such as magnetite $\left(\mathrm{Fe}_{3} \mathrm{O}_{4}\right)$ may be prepared using various chemical techniques such as co-precipitation, sol-gel response, hydrothermal, synthesis of fluid injection, polyol process, sonolysis, electrochemical process, and aerosol process [17]. Iron oxides $\left(\mathrm{Fe}_{3} \mathrm{O}_{4}\right.$ or $\left.\pi \mathrm{Fe}_{2} \mathrm{O}_{3}\right)$ are commonly formed by an aging stoichiometric mixture of ferrous and ferric salts in aqueous media [18]. Yet natural iron sand may also be used to synthesize magnetic nanoparticles in addition to the Iron (II) and (III) salts. The synthesis of magnetic nanoparticles such as magnetite $\left(\mathrm{Fe}_{3} \mathrm{O}_{4}\right)$ from natural iron-sand would improve its economic benefit and increase future applications.

Moreover, oxidation can occur with as-prepared magnetite nanoparticles. Surface alteration with certain long inter-chain molecules is often necessary for strengthening colloidal and magnetic stability [19]. High magnetic and colloidal stability was achieved with various polymer surfactants such as poly (D,L-lactide-co-glycolide) [20], polyacrylamide [21], polymethacrylic acid, polystyrene, polyaniline, and polymethylmethacrylate [22]. As a biocompatible functional polymer composed of 1,4-D-glucopyranosyl repeated units: amylose and amylopectin, starch may also be used. Starch has high hydrophilic and biodegradable behaviors and is thus present in many kinds of applications [23].

In this article, a starch-coated magnetite particle was prepared from the natural iron sand. The proof of starch alteration in the magnetite nanoparticle was tested by FT-IR, XRD, SEM, and EDX. Adsorption of starch-coated magnetite nanoparticles and their magnetic properties are reported.

\section{Materials and Methods}

\subsection{Synthesis of MNPs.}

All the chemicals used were commercially available and of analytical grade. Hydrochloric acid $(\mathrm{HCl})$ and Sodium Hydroxide $(\mathrm{NaOH})$ were purchased from Kosdaq, Korea. Starch was purchased from Sigma-Aldrich.

This synthesis followed the co-precipitation procedure carried out by Berger et al. [24]. The Muddy iron was milled with the help of mortar and pestle. 130 gram of sample (muddy iron) was dissolved in $400 \mathrm{ml}$ of Hydrochloric acid $(25 \% \mathrm{HCl})$. The mixture was heated up to $80^{\circ} \mathrm{C}$ with 700rpm stirring for one hour. The precipitation of $\mathrm{Fe}_{3} \mathrm{O}_{4}$ took place after the addition of Sodium hydroxide $(\mathrm{NaOH})$ to the mixture the $\mathrm{pH}$ value reached 12.

The magnetic nanoparticles $\left(\mathrm{Fe}_{3} \mathrm{O}_{4}\right)$ were then heated up to $70^{\circ} \mathrm{C}$ for 30 minutes, followed by cooling at room temperature. The MNP precipitate was then washed with distilled water several times. Starch solutions with various concentrations have been prepared for the synthesis of starch-coated MNPs by dissolving starch at $50^{\circ} \mathrm{C}$ in hot water. Under intense 
stirring at $70^{\circ} \mathrm{C}$ for 3 hours, the synthesized natural Iron magnetic nanoparticles were poured into various starch solutions. The remaining solution was then cooled and stored for 24 hours at room temperature, and the gel was formed. The shaped gels were then washed several times with de-ionized water until the $\mathrm{pH}$ was less than 8 (Figure1).
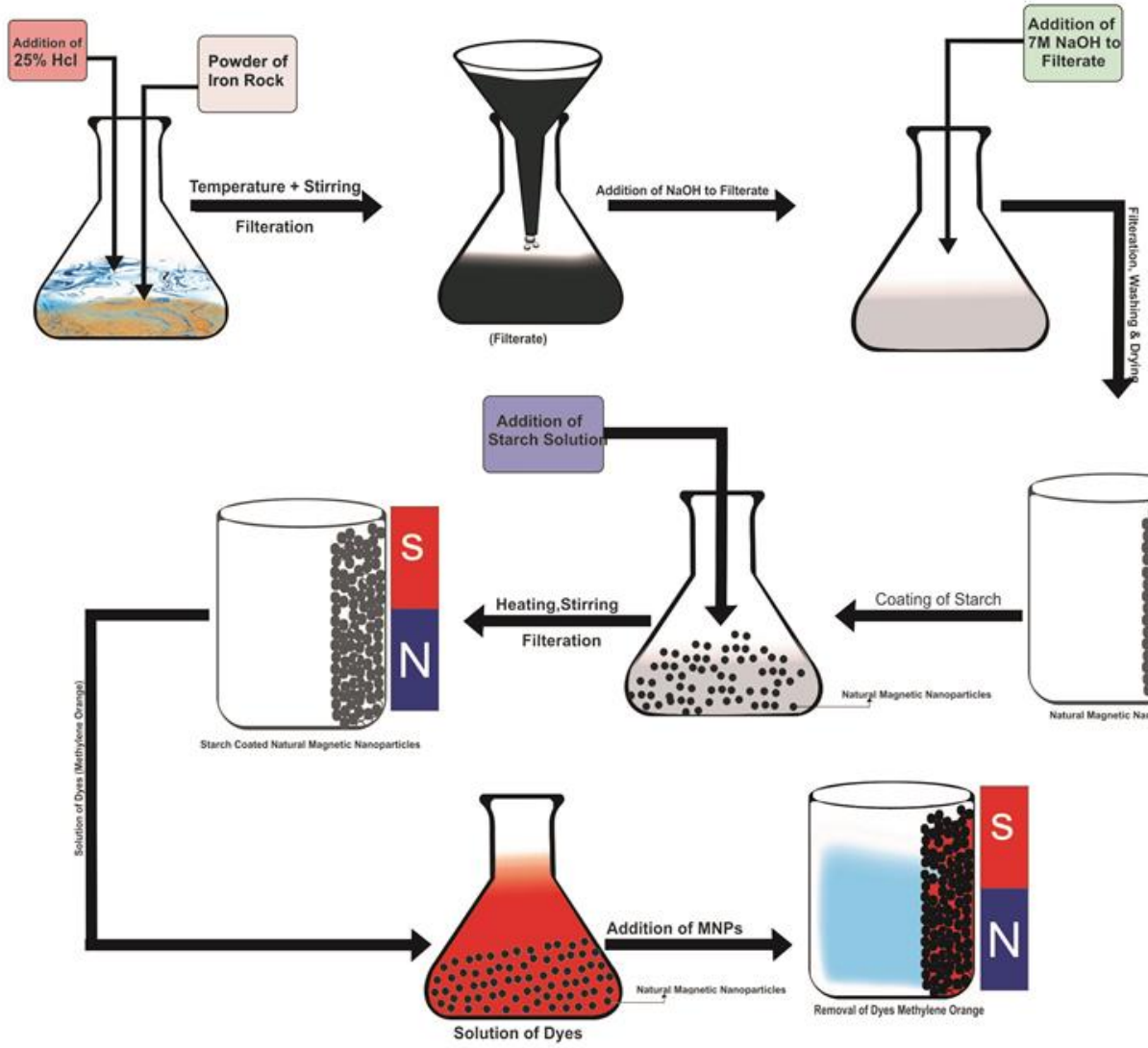

Figure 1. The synthetic procedure of non-coated and starch coated iron oxide magnetic nanoparticles.

\subsection{Characterization of MNPs.}

\subsubsection{Elemental Analysis by EDX.}

Energy-dispersive X-ray analysis was used to evaluate the elemental iron content in the colloidal suspension of MNPs (EDX).

\subsubsection{Scanning electron microscopy (SEM).}

The morphology of MNPs was observed with an SEM microscope (Model: JSM5910 JEOL, Japan) at $5 \mathrm{kV}$.

\subsubsection{X-Ray Diffraction.}

$\mathrm{X}$-ray diffraction (XRD) was performed using Japan D/MAX-RB for phase evaluation. The mean crystallite sizes of $\mathrm{Fe}_{3} \mathrm{O}_{4}$ spherulites of the powders were determined using the XRDScherrer formula (mean crystallite size $=0.9 \lambda /(B \cos \theta)$, where $B=$ broadening of width at the half-peak height (WHPH) in radians and $\theta=$ Bragg angle). It was applied to peaks of the (110) plane of $\alpha-\mathrm{Fe}_{3} \mathrm{O}_{4}$ and (311 or 222) plane of $\mathrm{Fe}_{3} \mathrm{O}_{4}$, respectively, at a scanning rate of $0.5^{\circ} \mathrm{min}^{-}$ 1 . 
2.2.4. FT-IR analysis of pure and starch coated $\mathrm{Fe}_{3} \mathrm{O}_{4}$.

FT-IR (Fourier transform infrared) analysis was performed in Material Research Laboratory (MRL), Department of Physics, University of Peshawar, Khyber Pakhtunkhwa, Pakistan.

\section{Results and Discussion}

\subsection{FT-IR analysis of pure and starch coated $\mathrm{Fe}_{3} \mathrm{O}_{4}$.}

Figure 1(a) shows the findings of FT-IR analysis of non-coated Iron nanoparticles. It illustrates the typical magnetite nanoparticles band at $576 \mathrm{~cm}^{-1}$ due to $\mathrm{Fe}-\mathrm{O}$ vibration and band at $1462 \mathrm{~cm}^{-1}$ is assigned to $\mathrm{Fe}-\mathrm{O}$ stretching, and the band at approximately $4000 \mathrm{~cm}^{-1}$ is due to the stretching vibrations of surface $-\mathrm{OH}$ groups. The FT-IR spectra of starch-coated nanoparticles shown in Figure 1(b) exhibit two spectra at the range of $437 \mathrm{~cm}^{-1}$ and $563 \mathrm{~cm}^{-1}$; it shows typical Fe-O vibrations of the maghemite structure. The bending vibration shows water absorption at the range of $1600 \mathrm{~cm}^{-1}$. New bands in 834,1021 , and $1479 \mathrm{~cm}^{-1}$ aligned with acetal groups of amylose and amylopectin in starch have appeared in the FT-IR spectra. C-O stretching vibrations in the C-O-H groups are expressed by peaks at 834 and $1021 \mathrm{~cm}^{-1}$, while the $834 \mathrm{~cm}^{-1}$ peak refers to the $\mathrm{C}-\mathrm{O}$ stretching vibration in the $\mathrm{C}-\mathrm{O}-\mathrm{C}$ groups. The peaks at $1677 \mathrm{~cm}^{-1}$ are assigned to $\delta(\mathrm{O}-\mathrm{H})$ bending of water and hydrogen-bonded hydroxyl groups of amylose and amylopectin of starch. The Fe-O stretching vibration can be assigned to the absorption bands at 437 and $563 \mathrm{~cm}^{-1}$ for $\gamma-\mathrm{Fe}_{2} \mathrm{O}_{3}$ nanoparticles.

(a)

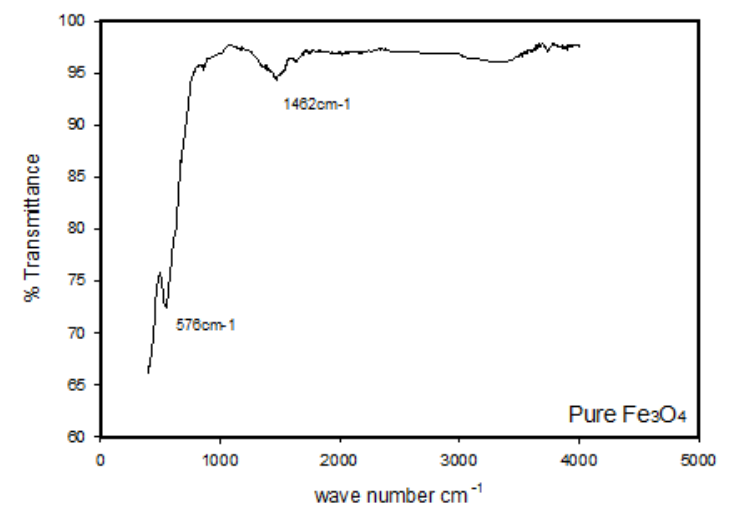

(b)

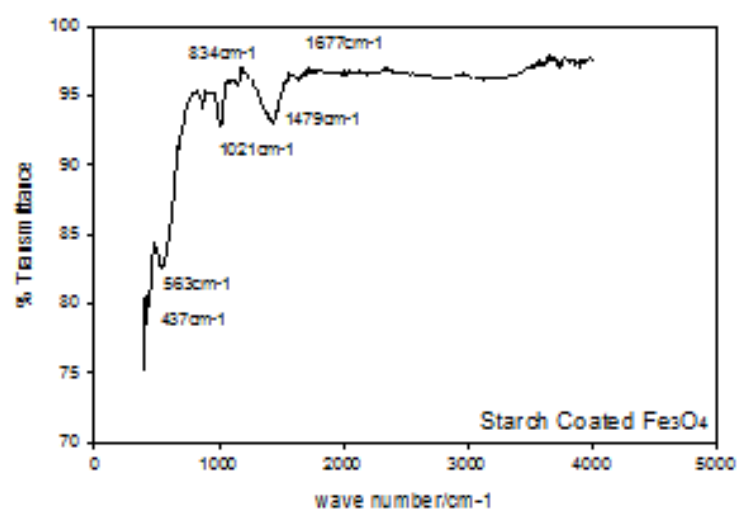

Figure 2. (a) FT-IR spectra of non-coated iron nanoparticles; (b) The FT-IR spectra of starch coated nanoparticles.

\subsection{XRD analysis of pure and starch coated $\mathrm{Fe}_{3} \mathrm{O}_{4}$ nanoparticles.}

Figure 3(a) shows the XRD analysis of non-coated $\mathrm{Fe}_{3} \mathrm{O}_{4}$ nanoparticles. The result shows that iron ore contains many natural crystals like $\mathrm{Al}_{2} \mathrm{O}_{3}(311), \mathrm{Fe}_{2} \mathrm{O}_{3} / \mathrm{Fe}_{3} \mathrm{O}_{4}$ (511) in small quantity, and also it contains Quartz (200), in major quantity, which is the pure form of sand and too expensive. Milled iron rocks, co-precipitated $\mathrm{Fe}_{3} \mathrm{O}_{4}$, and $\mathrm{Fe}_{3} \mathrm{O}_{4}$ samples consist of a single phase of magnetite $\left(\mathrm{Fe}_{3} \mathrm{O}_{4}\right)$ with spinel cubic structures. It can be seen that materials have a dominant composition of $\mathrm{Fe}_{3} \mathrm{O}_{4}$ with a magnetite phase. The hydrophilic nature of the surface of the magnetite nanoparticle precludes its dispersion into water. On the nanoparticles' surface, starch is chemisorbed, which renders the particles hydrophobic, so these nanoparticles become dispersible in water. The XRD pattern was used to identify the iron oxide phase of the 
electrodeposited Powder. In Figure 3(b), all the peak positions at 28.4 (200), 34.7 (311), 38.7 (400), 56.1 (511), 63.5 (440) are consistent with the standard X-ray data for the Magnetite phase. No additional peaks were observed. So, the XRD pattern verified the magnetite phase of starch coated Iron nanoparticles sample.

(a)

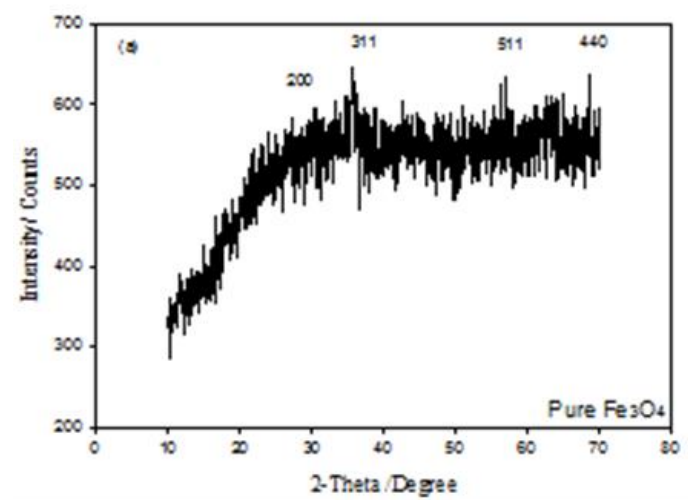

(b)

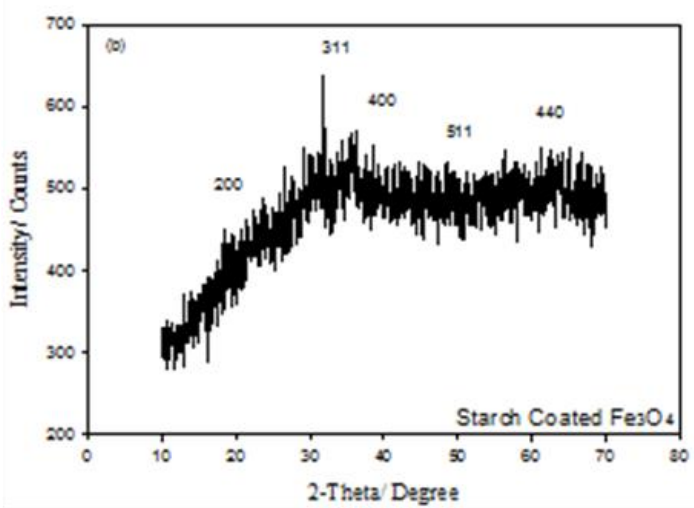

Figure 3. (a) The XRD analysis result of non-coated $\mathrm{Fe}_{3} \mathrm{O}_{4}$ nanoparticles; (b) The XRD analysis result of starch coated $\mathrm{Fe}_{3} \mathrm{O}_{4}$ nanoparticles.

\subsection{EDX analysis of pure and starch coated $\mathrm{Fe}_{3} \mathrm{O}_{4}$ nanoparticles.}

The energy dispersive X-ray (EDX) spectra show the existence of $\mathrm{Fe} 75.63 \%, \mathrm{O}$ $16.29 \%, \mathrm{Na} 0.85 \%, \mathrm{Cl} 1.75 \%, \mathrm{Ca} 3.95 \%$ and $\mathrm{C} 1.52 \%$ as key elements in the samples (Table 1) (Figure 4(a)). Detection of $\mathrm{C}$ element shows the successful coating of starch on $\mathrm{Fe}_{3} \mathrm{O}_{4}$. Again, the presence of elements like $\mathrm{Fe}, \mathrm{C}, \mathrm{O}, \mathrm{Ca}, \mathrm{Cl}$, and the successful incorporation of starch coated $\mathrm{Na}$ indicates $\mathrm{Fe}_{3} \mathrm{O}_{4}$ in the spectrum. While EDX results from starch-coated $\mathrm{Fe}_{3} \mathrm{O}_{4}$ show a decreased weight $\%$ in every element due to coating of starch for stabilization. Fe $55.89 \%, \mathrm{O}$ $18.68 \%, \mathrm{Na} 8.02 \%, \mathrm{Cl} 6.53 \%, \mathrm{Ca} 2.81 \%$ and $\mathrm{C} 8.05 \%$. (Table 2) (Figure 4(b)) shows the percentage of each element.

(a)

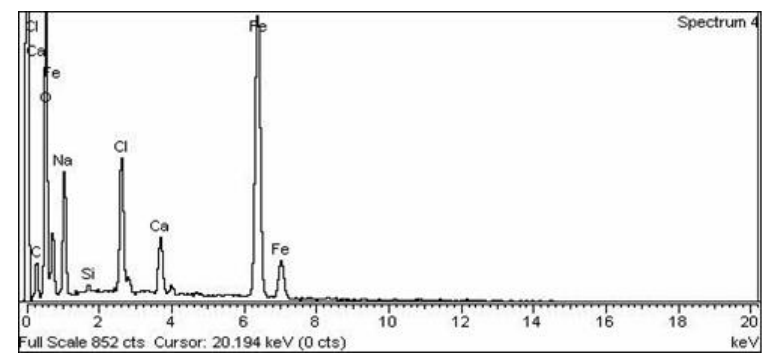

(b)

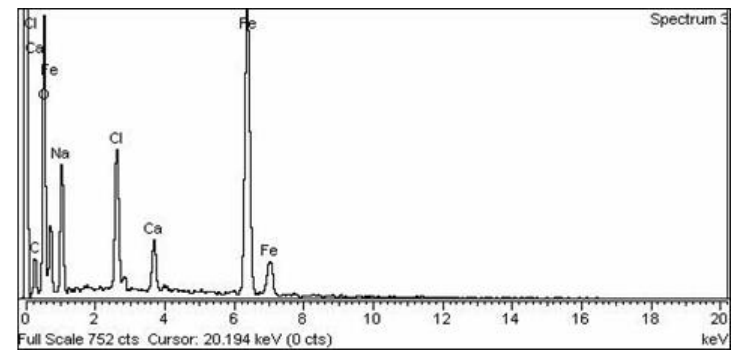

Figure 4. (a) EDX spectra of non-coated magnetic iron oxide nanoparticles; (b) EDX spectra of starch coated magnetic iron oxide nanoparticles.

Table 1. EDX result of pure $\mathrm{Fe}_{3} \mathrm{O}_{4}$.

\begin{tabular}{c|c|c} 
Element & Weight \% & Atomic \% \\
\hline $\mathrm{C} \mathrm{K}$ & 1.52 & 4.73 \\
\hline $\mathrm{O} \mathrm{K}$ & 16.29 & 37.93 \\
\hline $\mathrm{Na} \mathrm{K}$ & 0.85 & 1.38 \\
\hline $\mathrm{Cl} \mathrm{K}$ & 1.75 & 1.84 \\
\hline $\mathrm{Ca} \mathrm{K}$ & 3.95 & 3.67 \\
\hline $\mathrm{Fe} \mathrm{K}$ & 75.63 & 50.45 \\
\hline Total & 100.00 &
\end{tabular}


Table 2. EDX result of starch coated $\mathrm{Fe}_{3} \mathrm{O}_{4}$.

\begin{tabular}{c|c|c} 
Element & Weight \% & Atomic \% \\
\hline $\mathrm{C} \mathrm{K}$ & 8.05 & 19.48 \\
\hline $\mathrm{O} \mathrm{K}$ & 18.68 & 33.92 \\
\hline $\mathrm{Na} \mathrm{K}$ & 8.02 & 10.14 \\
\hline $\mathrm{Cl} \mathrm{K}$ & 6.53 & 5.35 \\
\hline $\mathrm{Ca} \mathrm{K}$ & 2.81 & 2.04 \\
\hline $\mathrm{Fe} \mathrm{K}$ & 55.89 & 29.07 \\
\hline Total & 100.00 & \\
\hline
\end{tabular}
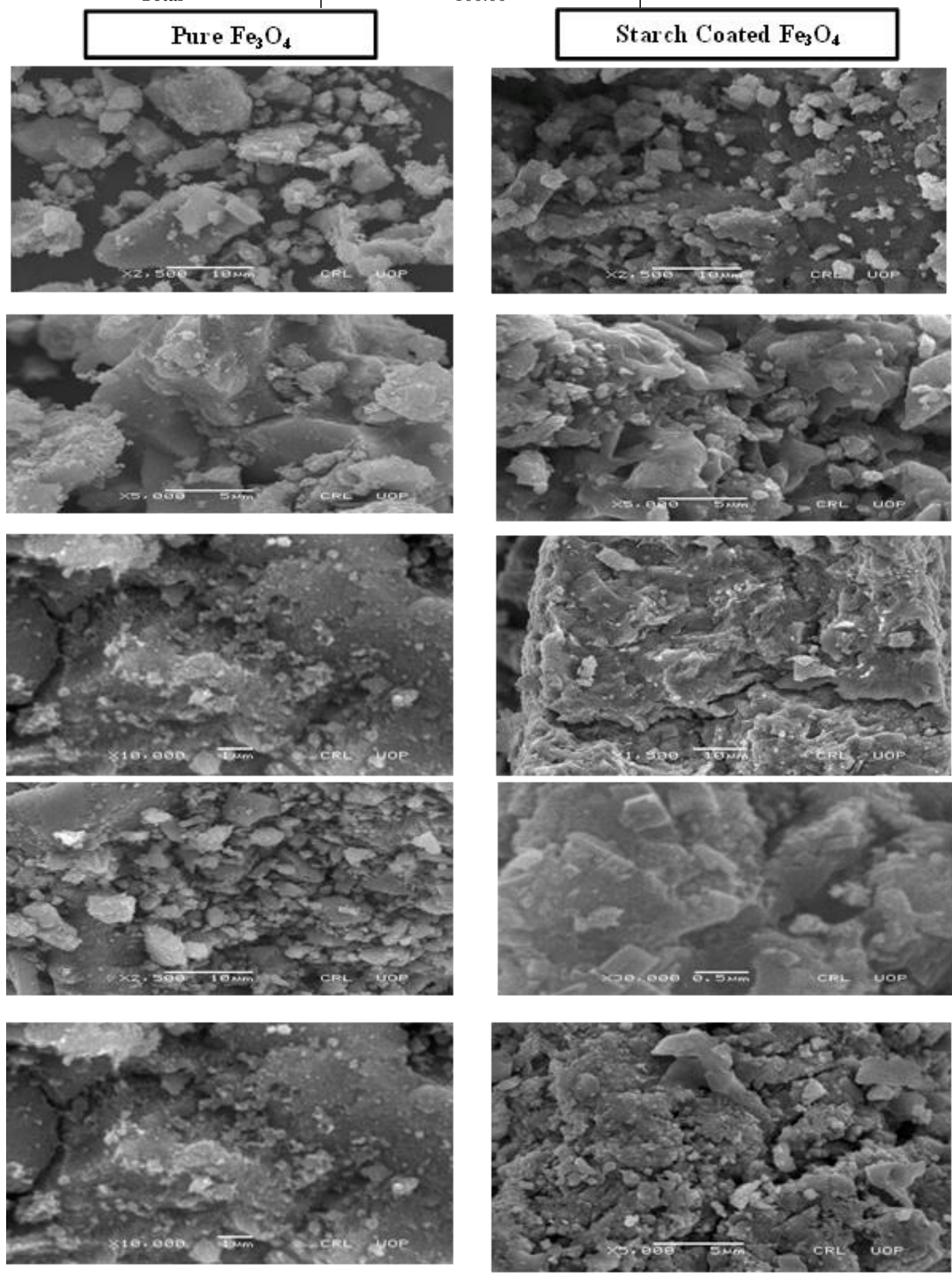

Figure 5. SEM images of pure and starch coated magnetic iron oxide nanoparticles. 


\subsection{Scanning Electron Microscopy (SEM).}

From the results of particle size analysis of the SEM images of starch coated $\mathrm{Fe}_{3} \mathrm{O}_{4}$, the morphological structures of pure and starch coated natural $\mathrm{Fe}_{3} \mathrm{O}_{4}$ nanoparticles have been investigated at the resolution of $X=2500, X=5000$. $X=10000, X=20000$ and $x=30000$. From SEM result it gives information about the pure and starch coated $\mathrm{Fe}_{3} \mathrm{O}_{4}$. It has been concluded that a single starch-coated iron oxide nanoparticle is made up of several magnetite cores and starch chains coating these cores (Figure 5).

\subsection{Adsorption study.}

Adsorption studies were conducted at room temperature. A series of $250 \mathrm{ml}$ flasks was filled with $100 \mathrm{ml}$ of the aqueous solution containing methyl orange. Each flask was then filled with a specified volume of adsorbent dosage.

\subsubsection{Effect of adsorbent dosage.}

Reasonable trials were performed at adsorbent dosages in the range of 1-10 g/L, initial methyl orange concentration $100 \mathrm{mg} / \mathrm{L}$, to establish the optimum adsorbent dose. The reduction of methyl orange improved as the adsorbent dosage increased. This was attributed to the increase in the surface area of starch-coated MPs and the availability of more adsorption sites (Figure 6).

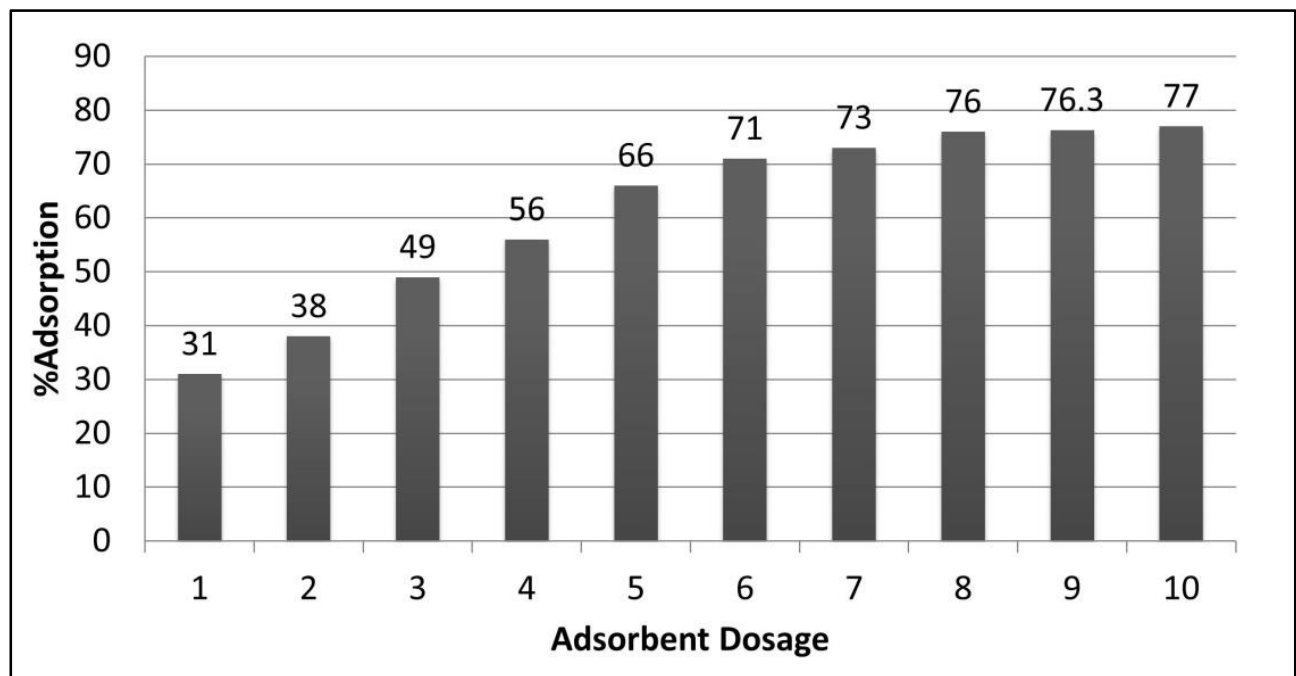

Figure 6. Effect of adsorbent dosage on percent adsorption of the methyl orange dye starch coated MNPs.

\subsubsection{Effect of $\mathrm{pH}$.}

The adsorption of methyl orange by starch-coated magnetic nanoparticles was studied under different $\mathrm{pH}$ environments. The effect of $\mathrm{pH}$ was checked from 2 to 10 . At $\mathrm{pH} 2$, the adsorption was very low due to the high concentration of $\mathrm{H}^{+}$, which protonate methyl orange and starch. The adsorption is maximum at $\mathrm{pH} 6$ because both methyl orange and starch are neutral, where it is $78 \%$ (Figure 7). 


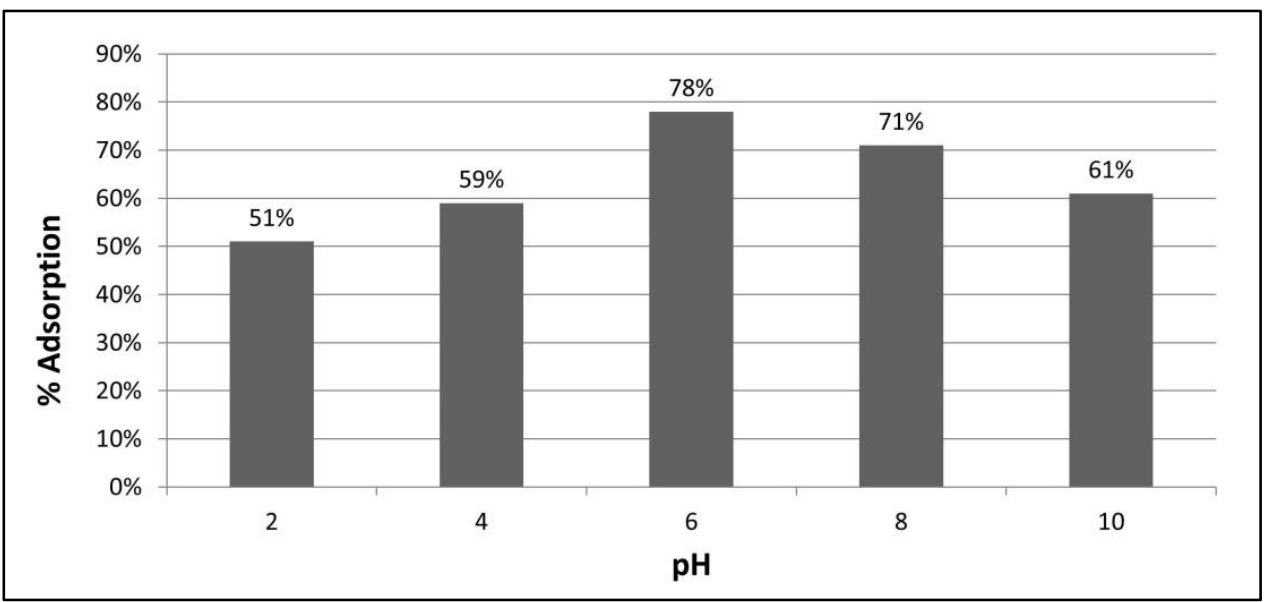

Figure 7. Effect of $\mathrm{pH}$ on percent adsorption of the methyl orange dye on starch coated MNPs.

\subsection{Effect of time.}

The effect of time on methyl orange adsorption on starch-coated MNPs was studied; the contact time was between 30 minutes and 160 minutes. At the 90 and 155 minutes, the adsorption rate was high. It's because the contact time was increase and MNPs were in contact with MO for maximum time (Figure 8).

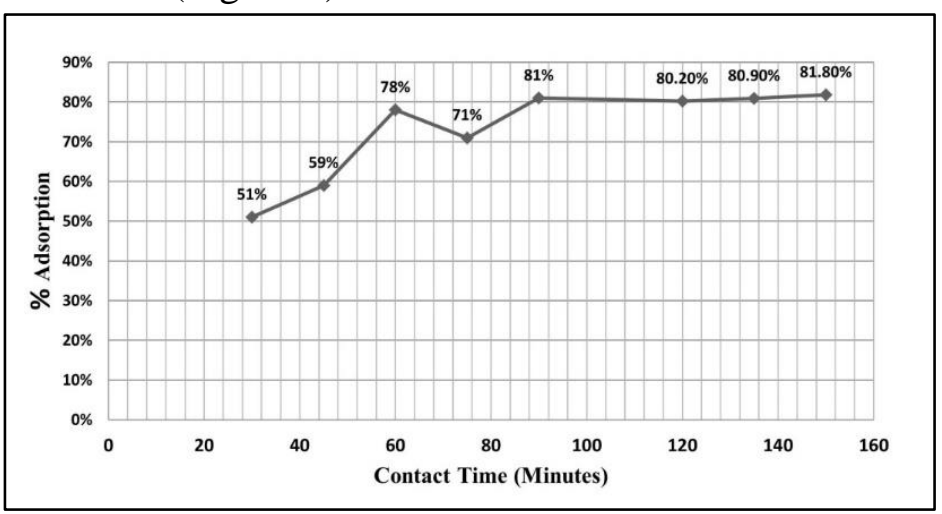

Figure 8. Effect of time on percent adsorption of the Methyl Orange dye on starch coated MNPs.

\section{Conclusions}

The samples $\mathrm{Fe}_{3} \mathrm{O}_{4}$ have been successfully extracted by the co-precipitation method from natural iron rocks. Magnetite nanoparticles coated with starch were prepared and examined. Starch-coated magnetite nanoparticles are confirmed to have fair magnetic properties, high biocompatibility, and high colloidal and magnetic stability. This means that it is possible to accept starch-coated magnetite nanoparticles as bio-potential materials for applications. The functional group analysis using FT-IR indicates that transmittance peaks of iron rock extraction occurred at wave numbers about $559 \mathrm{~cm}^{-1}$ that revealed the existence of vibrations of the $\mathrm{Fe}-\mathrm{O}$ bond. XRD analysis shows the crystalline structure at $311 \mathrm{~A}^{\mathrm{o}}$ of nanoparticles. EDX result shows its elemental composition of up to $75 \%$ Fe present in natural rocks. SEM results show its morphological structure of pure and coated nanoparticles. Methyl orange dye, which is very hazardous for marine life and human beings, has been successfully removed from an aqueous solution by starch-coated natural iron nanoparticles up to $78 \%$.

\section{Funding}

This research received no external funding. 


\section{Acknowledgments}

The authors thank the Department of Chemistry, Abdul Wali Khan University Mardan, and Advanced Material and Analysis Research Laboratory Peshawar, Pakistan, to support and provision of required chemicals and glassware.

\section{Conflicts of Interest}

The authors declare no conflict of interest.

\section{References}

1. Singh, N.A. Nanotechnology innovations, industrial applications and patents. Environ. Chem. Lett. 2017, 15, 185-191, http://doi.org/10.1007/s10311-017-0612-8.

2. Maher, K.O. Nanomedicine and nanotechnology for heart failure research, diagnosis, and treatment. In Heart failure in the child and young adult, Elsevier: 2018; 779-784.

3. Kargozar, S.; Mozafari, M. Nanotechnology and Nanomedicine: Start small, think big. Materials Today: Proceedings 2018, 5, 15492-15500, http://doi.org/10.1016/j.matpr.2018.04.155.

4. El-Sayed, A.; Kamel, M. Advanced applications of nanotechnology in veterinary medicine. Environmental Science and Pollution Research 2020, 27, 19073-19086, http://doi.org/10.1007/s11356-018-3913-y.

5. Asif, A.; Hasan, M.Z. Application of nanotechnology in modern textiles: A review. International Journal of Current Engineering and Technology 2018, 8, 227-231, https://doi.org/10.14741/ijcet/v.8.2.5.

6. Salleh, A.; Naomi, R.; Utami, N.D.; Mohammad, A.W.; Mahmoudi, E.; Mustafa, N.; Fauzi, M.B. The Potential of Silver Nanoparticles for Antiviral and Antibacterial Applications: A Mechanism of Action. Nanomaterials 2020, 10, http://doi.org/10.3390/nano10081566.

7. Javed, R.; Zia, M.; Naz, S.; Aisida, S.O.; Ain, N.u.; Ao, Q. Role of capping agents in the application of nanoparticles in biomedicine and environmental remediation: recent trends and future prospects. Journal of Nanobiotechnology 2020, 18, 172, http://doi.org/10.1186/s12951-020-00704-4.

8. Li, Y.; Xin, J.; Sun, Y.; Han, T.; Zhang, H.; An, F. Magnetic resonance imaging-guided and targeted theranostics of colorectal cancer. Cancer biology \& medicine 2020, 17, 307-327, https://doi.org/10.20892/j.issn.2095-3941.2020.0072.

9. Safarik, I.; Baldikova, E.; Prochazkova, J.; Pospiskova, K. Magnetic particles in algae biotechnology: recent updates. J. Appl. Phycol. 2020, 32, 1743-1753, http://doi.org/10.1007/s10811-020-02109-0.

10. Zhou, Z.; Yang, L.; Gao, J.; Chen, X. Structure-Relaxivity Relationships of Magnetic Nanoparticles for Magnetic Resonance Imaging. Adv. Mater. 2019, 31, 1804567, http://doi.org/10.1002/adma.201804567.

11. Tran, M.V.; Susumu, K.; Medintz, I.L.; Algar, W.R. Supraparticle Assemblies of Magnetic Nanoparticles and Quantum Dots for Selective Cell Isolation and Counting on a Smartphone-Based Imaging Platform. Anal. Chem. 2019, 91, 11963-11971, http://doi.org/10.1021/acs.analchem.9b02853.

12. Gawali, S.L.; Barick, B.K.; Barick, K.C.; Hassan, P.A. Effect of sugar alcohol on colloidal stabilization of magnetic nanoparticles for hyperthermia and drug delivery applications. J. Alloys Compd. 2017, 725, 800806, http://doi.org/10.1016/j.jallcom.2017.07.206.

13. Jeevanandam, J.; Barhoum, A.; Chan, Y.S.; Dufresne, A.; Danquah, M.K. Review on nanoparticles and nanostructured materials: history, sources, toxicity and regulations. Beilstein journal of nanotechnology 2018, 9, 1050-1074, http://doi.org/10.3762/bjnano.9.98.

14. Wu, L.; Zhang, J.; Watanabe, W. Physical and chemical stability of drug nanoparticles. Adv. Drug Del. Rev. 2011, 63, 456-469, http://doi.org/10.1016/j.addr.2011.02.001.

15. Khatami, M.; Alijani, H.Q.; Fakheri, B.; Mobasseri, M.M.; Heydarpour, M.; Farahani, Z.K.; Khan, A.U. Super-paramagnetic iron oxide nanoparticles (SPIONs): Greener synthesis using Stevia plant and evaluation of its antioxidant properties. Journal of Cleaner Production 2019, 208, 1171-1177, http://doi.org/10.1016/j.jclepro.2018.10.182.

16. Sui, Y.; Liu, X.; Liu, C. Room temperature ferromagnetic property of Fe-Y (Fe: Y-6.5) composite oxide nano-cluster via an extremely easy and scalable method. Journal of Rare Earths 2020, 5-10, http://doi.org/10.1016/j.jre.2020.07.009.

17. Hasany, S.F.; Ahmed, I.; Rajan, J.; Rehman, A. Systematic review of the preparation techniques of iron oxide magnetic nanoparticles. Nanosci. Nanotechnol 2012, 2, 148-158, http://doi.org/10.5923/j.nn.20120206.01. 
18. Nisticò, R. A synthetic guide toward the tailored production of magnetic iron oxide nanoparticles. Boletín de la Sociedad Española de Cerámica y Vidrio 2021, 60, 29-40, http://doi.org/10.1016/j.bsecv.2020.01.011.

19. Krajewski, M.; Brzozka, K.; Tokarczyk, M.; Kowalski, G.; Lewinska, S.; Slawska-Waniewska, A.; Lin, W.S.; Lin, H.M. Impact of thermal oxidation on chemical composition and magnetic properties of iron nanoparticles. J. Magn. Magn. Mater. 2018, 458, 346-354, http://doi.org/10.1016/j.jmmm.2018.03.047.

20. Chun, S.H.; Shin, S.W.; Amornkitbamrung, L.; Ahn, S.Y.; Yuk, J.S.; Sim, S.J.; Luo, D.; Um, S.H. Polymeric Nanocomplex Encapsulating Iron Oxide Nanoparticles in Constant Size for Controllable Magnetic Field Reactivity. Langmuir 2018, 34, 12827-12833, http://doi.org/10.1021/acs.langmuir.7b04143.

21. Ma, J.; Fu, X.; Jiang, L.; Zhu, G.; Shi, J. Magnetic flocculants synthesized by Fe3O4 coated with cationic polyacrylamide for high turbid water flocculation. Environmental Science and Pollution Research 2018, 25, 25955-25966, http://doi.org/10.1007/s11356-018-2610-1.

22. Mohammadi Ziarani, G.; Malmir, M.; Lashgari, N.; Badiei, A. The role of hollow magnetic nanoparticles in drug delivery. RSC Advances 2019, 9, 25094-25106, http://doi.org/10.1039/c9ra01589b.

23. Ziegler-Borowska, M. Magnetic nanoparticles coated with aminated starch for HSA immobilization- simple and fast polymer surface functionalization. Int. J. Biol. Macromol. 2019, 136, 106-114, http://doi.org/10.1016/j.ijbiomac.2019.06.044.

24. Berger, P.; Adelman, N.B.; Beckman, K.J.; Campbell, D.J.; Ellis, A.B.; Lisensky, G.C. Preparation and Properties of an Aqueous Ferrofluid. J. Chem. Educ. 1999, 76, 943. 